\title{
Evaluation of an Innovative Diagnostic Method for Detection of Antibodies and Antigens
}

\author{
Mandana Asalkhou, Navid Alem, Neda A. Ahmadi, Nina Hamedi, Mehdi Alem \\ Micro Detect, Inc., Tustin, USA \\ Email: malem@sbcglobal.net
}

How to cite this paper: Asalkhou, M., Alem, N., Ahmadi, N.A., Hamedi, N. and Alem, M. (2017) Evaluation of an Innovative Diagnostic Method for Detection of Antibodies and Antigens. International Journal of Clinical Medicine, 8, 306-321. https://doi.org/10.4236/ijcm.2017.85029

Received: April 12, 2017

Accepted: May 23, 2017

Published: May 26, 2017

Copyright $\odot 2017$ by authors and Scientific Research Publishing Inc. This work is licensed under the Creative Commons Attribution International License (CC BY 4.0).

http://creativecommons.org/licenses/by/4.0/

\begin{abstract}
Reports manifest a continuing need for the development of rapid and on-site (point of care) assays. Current diagnostic methods commonly used for detection of antibodies and antigens have significant limitations. Scientists at Micro Detect, Inc. have developed an innovative diagnostic device (method) that can be utilized broadly for antibody/antigen interactions including diagnostic assays in the medical, veterinary and food industries. The developed device can be utilized for the detection of antibodies against a single antigen or vice versa. It can also be tailored for specific panels that detect antigens or antibodies for diverse infectious agents, proteins, hormones, tumor markers, autoimmune markers, and allergens. Additionally, it can also be used for detection of toxins, antitoxins, nucleic acids, enzymes, drugs, etc. in both humans and animals. Specimens used in different formats of the device can be tears, saliva, whole blood, serum, plasma, urine, stool, and other bodily discharges. The good intra and inter precisions and acceptable linearity of the device support reliable use of the device. The CV of the device is $1.9 \%-2.2 \%$. Likewise, the performance of the device using 92 confirmed negative and positive specimens via a typical assay showed $100 \%$ sensitivity, $80 \%$ specificity, $96.8 \%$ efficacy, $80 \%$ positive predictive value, and $100 \%$ negative predictive value. The results of our feasibility study suggest reliable utility of a device for rapid, easyto-use, inexpensive, and on-site (point of care) diagnostic assays. This presents a potential breakthrough in diagnostic methodologies that can be integrated into modern medicine and food industries.
\end{abstract}

\section{Keywords}

Rapid Diagnostic Test, UV Laser Spectroscopy,

Panel Antibody/Antigen Assays, Point of Care Testing

\section{Introduction}

A significant number of diagnostic tests routinely performed in the medical, ve- 
terinary and food industries integrate antigen antibody interactions. Routinely, either a specific antibody is used to detect presence of a specific antigen or a specific antigen is used to detect presence of a specific antibody. The diagnostic methods that are implemented include agglutination, western blot, ELISA, RIA, immune diffusion, complement fixation, lateral flow (one-step), and PCR (limited application). Of these methods, ELISA and lateral-flow are the most commonly utilized.

In lateral-flow, which can also be considered as an on-site method delivering rapid results, gold or colored latex particles are coated with specific antigens or antibodies. In a positive specimen, the known antibodies or antigens fixed on a membrane capture corresponding antigens or antibodies coated on the gold or latex particles. Although this method has several limitations and cannot be widely used, for the detection of certain analytes and screening purposes, it remains the best choice. This method has enhanced performance when the detection of an antigen is the aim of the test and when the concentration of detectable antigens or antibodies in the sample is relatively elevated. With lateral-flow, the borderline positive or negative specimens may produce false negative or false positive results. This method is mostly used for the detection of a single analyte. Recently, devices that can measure up to 4 analytes, especially for drugs abuse assays, have been developed.

For certain disease states, measuring the titers of a certain antibody (IgG, IgM, IgA or IgE) in provided patient specimens is integral to monitor disease severity and stage. For this reason, the ELISA method is often the best choice. In ELISA, a known and specific antigen is fixed in the wells of microplates. After addition of a patients' specimen, addition of the second corresponding anti-antibody conjugate, and addition of the substrate, the titers of the first antibodies in the specimens are measured via ODs using a spectrophotometer. In ELISA, the second antibody is mostly conjugated with an enzyme or a florescent dye. ELISA can be used for measuring the titers of the antibodies in several specimens against a single antigen or for the detection of different antibodies against specific antigens. Performing ELISA assays necessitates skilled technicians and should be done in a clinical laboratory setting. This method consists of several reagents and incubation times, as such, ELISA is not considered as a rapid result test.

The market for rapid medical diagnostic tests (on-site) in the United States was estimated at $\$ 19.4$ billion in 2014 [1]. The global market for the development of rapid diagnostic methodology has demonstrated accelerated growth over the past few years and this trend is likely to sustain. It is anticipated that the total market in the United States alone will increase to $\$ 27$ billion by 2020 . Considering the global market as well, this number will only exponentially grow [2]. Rapid on-site testing can provide valuable insight for physicians in a multitude of settings by expediting implementation of therapeutic plans. This is a particularly important time for such a breakthrough in diagnostic methodology as the healthcare industry is evolving to leverage escalating costs. The screening of the 
infectious agents or their toxins in the food industry is also an expansive market, estimated to have a fiscal burden of $\$ 27$ billion in 2012 [3].

Development of a fast, on-site, inexpensive, and easy to use diagnostic method has significant promise for both the medical and food industries. Scientists at Micro Detect, Inc. have developed such a method/device (patent pending). The innovative technology, UV Laser Spectroscopy Diagnostic (UVLSD) ${ }^{1}$ developed at Micro Detect, Inc. has the ability to readily detect antigens or antibodies from either single or multiple analytes (specific panels). This includes pathogenic infectious agents (viruses, bacteria, fungi, chlamydia, and/or protozoa), antibodies to autoimmune markers, and allergens. It can also be used for detection of toxins, antitoxins, proteins, nucleic acids, enzymes, hormones, tumor markers, and drugs in humans and animals. Likewise, it may be employed for the detection of certain pathogenic microorganisms and/or their toxins in the food industry or plant pathology discipline. The device can also be tailored to measure the presence of specific antibody classes against a specific antigen in either single or multiple specimens. The specimens used in this newly developed diagnostic technology can be tears, saliva, whole blood, serum, plasma, urine, stool, and other body discharges of animals or humans. In the food industry, the extracts of foods containing microorganisms or their toxins may be utilized.

\section{Material and Methods}

\subsection{Solid Phase}

The solid phase is a support material that supports active "sites" where antigens or antibodies are coated. The solid phase by itself can be the active sites of the device. In other words, the solid phase can be something similar to a credit card or the chips mounted on a credit card. The active parts of the device can be activated charcoal, plastic, gold, nitrocellulose membrane, latex, silicon or similar material. The antigens or antibodies should be immobilized on the active parts of the device. Coating can be on single or on multiple spots of the device. On a single solid phase, antigens or antibodies can be immobilized in a single spot of the active sites. For example, devices have the ability to detect specific IgE antibodies against a single allergen. To detect specific IgE antibodies to multiple allergens in a specimen in one run, many allergens can be coated at different spots of the solid phases' active sites.

To show the feasibility in the study presented in this article, activated slides coated with CodeLink ${ }^{\circledast}$ HD, Surmodics, Inc., Eden Prairie, MN were mostly used as active sites.

In this study, for confirmation of the performance of the prototype detector and to demonstrate feasibility of the device, the data were obtained from a 200 $\mu \mathrm{m}$ field of the active sites. This means that in an active site area as big as $1^{2}$ centimeter, at least 20 - 30 analytes could be coated. Example: 4 different antibodies to 4 major pathogens in a single food sample. The detection fields can be altered to higher or lower than $200 \mu \mathrm{m}$.

${ }^{1}$ Patent pending. 


\subsection{Principle and Procedure of the Method (Device)}

The principle of the method presented in this study correlates directly with the inherent nature of proteins. Different proteins have varied and specific physical and chemical properties (charges), folding, stability, activity, and ultimately, specific functions. Antigens, antibodies, enzymes, allergens are all proteins or feature proteins as their main constituents. Each protein has its own net positive or net negative charges which are mainly related to their active or binding sites. They also have specific sizes (MW), shapes and configurations. The size of a protein (example: an antigen) is smaller in comparison to the same protein that is also bond to another protein (example an antibody) or vice versa. Likewise, the size of a protein/antibody complex is smaller than the size of a bound antigen/antibody/second antibody complex. Since proteins absorb UV light at 280 $\mathrm{nm}$, larger sized proteins absorb more UV light (Example: antigen/antibody complex absorb more than an antigen alone). These fundamental properties for proteins were utilized in the development of the device presented in this study. Depending on the ultimate aims and design of the device, antibodies can be monoclonal or polyclonal.

The procedures and methods associated with the device include purified specific antigen or antibodies immobilized or coated on the active sites of the solid phase. After a reasonable incubation time, the non-specific binding sites on the solid phase were blocked by a solution containing a protein that did not interfere with the assay. After the blockage step, excess and unbound blocker was removed by washing and then slides were dried. This initial procedure should be done at manufacturing facilities and can easily be tailored towards the anticipated aims of device use.

On site, in diverse settings including laboratories, emergency rooms, ambulances, ambulatory physician offices, the end user operator(s) first read(s) the data (numerical or curve) by the detector at different spots of the device's sites where specific antigens or antibodies are coated. Reading the data on the device depends on the design of the detector and should take approximately 1 minute. The numerical data obtained after the first reading is used as the base absorptions values (UV.D.). The specimen is then added at different parts of the active sites, where diverse antigens or antibodies are fixed. The specific antibodies against specific coated antigens (or vice versa) bind to the corresponding analytes. After a short incubation, excess specimen is washed by a specific wash solution. After drying, the data (numerical or curved) is read by the detector and absorbed UV.Ds. are compared with the baseline absorption readings obtained before addition of the specimen. Only parts of the active sites on the solid phase, on which specific antibodies (or antigens) from the specimen are bound, exhibit a different molecular size and therefore an augmented absorption. The increase in absorption depends on the levels (titer) of the specific antibodies (or antigens) in the specimen. The highest concentrations of the specific antibodies (or antigens) present in the specimen directly correlate with the lowest readings. In other words, elevated antibodies (or antigens) in the specimen translate to increased absorption and therefore lower numbers. The entire time to perform single or 
multiple assays using the aforementioned technique is less than five minutes.

Using the device produces rapid, semi-quantitative data that can be used onsite for screening proposes.

If the application of the device is for detection of antibodies in multiple specimens against a single antigen (or vice versa) or if the aim is measuring the specific immunoglobulin (example: IgG) against an antigen, the device should be modified to prevent cross contamination. In this scenario, in order to measure the titer of a specific antibody to a specific antigen, the antigen/antibody complex is used as the baseline data and after addition of the second antibody to the device (example: Goat-anti-human IgG) and washing, the titer of IgG is measured numerically. Using the device for the purposes presented here is more complex and should be done in a laboratory setting by skilled personnel.

For any assay, the procedure should be optimized with cutoffs established.

\subsection{Reader/Detector}

Although promising data was obtained by using a Raman spectroscopy at 532 $\mathrm{nm}$ and UV micro spectroscopy, due to limitations including the size of the readers (not suitable for on-site testing) and a small detection field feasible for Raman spectroscopy $(2 \mu \mathrm{m})$ and UV micro spectroscopy $(100 \mu \mathrm{m})$, these readers were not used (patent pending).

In this study, a reader designed at Micro Detect, Inc. using Laser UV lights as the light source was operated. The designed UV system consists of a fiber optic multi-channel detection system that monitors and tracks changes in the optical transmission or reflection through a medium when utilizing a frequency modulated UV LED and a high sensitivity UV detector. This system uses a narrow bandwidth, high optical power, UV LED with peak emission intensity centered at $280 \mathrm{~nm}$ and a high sensitivity photodetector equipped with a band pass optical filter centered at $280 \mathrm{~nm}$ and a pass bandwidth of $\pm 30 \mathrm{~nm}$ from the center wavelength. The Laser UV reader system can be integrated into an instrument (such as a small instrument similar to a credit card reader) to monitor the light intensity activity of the UV after absorption of UV by biomolecules (proteins) immobilized on the surface of a solid phase. The reader can be designed in a manner allowing the detection site of the reader (heads) to directly transfer the data to a previously programmed cellular phone or electronic tablet.

As proteins absorb UV light (around $280 \mathrm{~nm}$ ), this device is mainly designed for the detection of proteins (most antigens and all antibodies are proteins). If the purpose of using this instrument is for detection of RNA or DNA, the wavelength can be changed to $260 \mathrm{~nm}$.

The prototype instrument designed at Micro Detect, Inc. can be used for transmission (Figure 1) or reflection (Figure 2).

\subsection{Specimens}

The specimens used in this study were sera, stools, urines, extract of bacteria, or urine or stool spiked by desired analytes. 


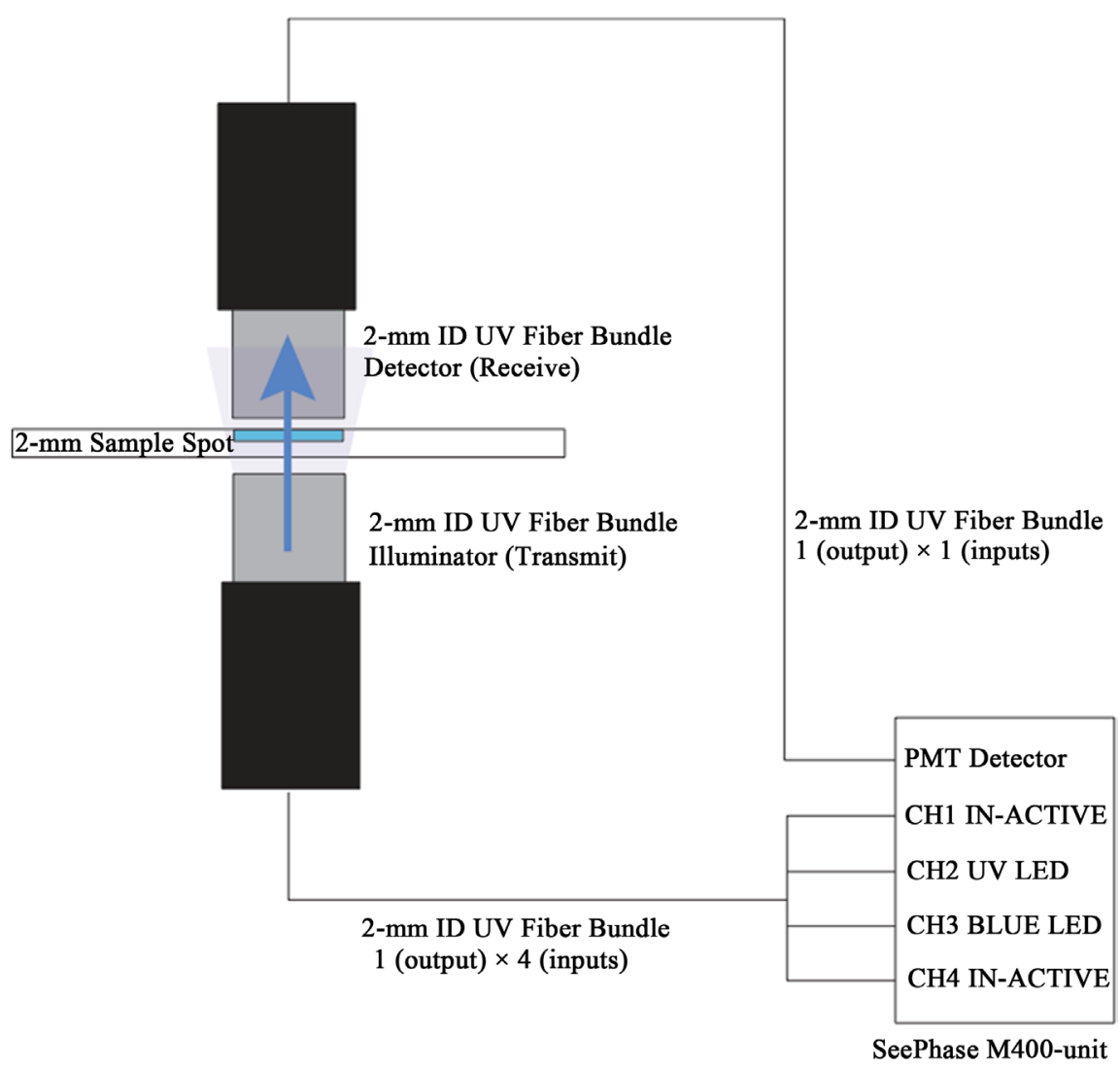

Figure 1. Transmission mode.

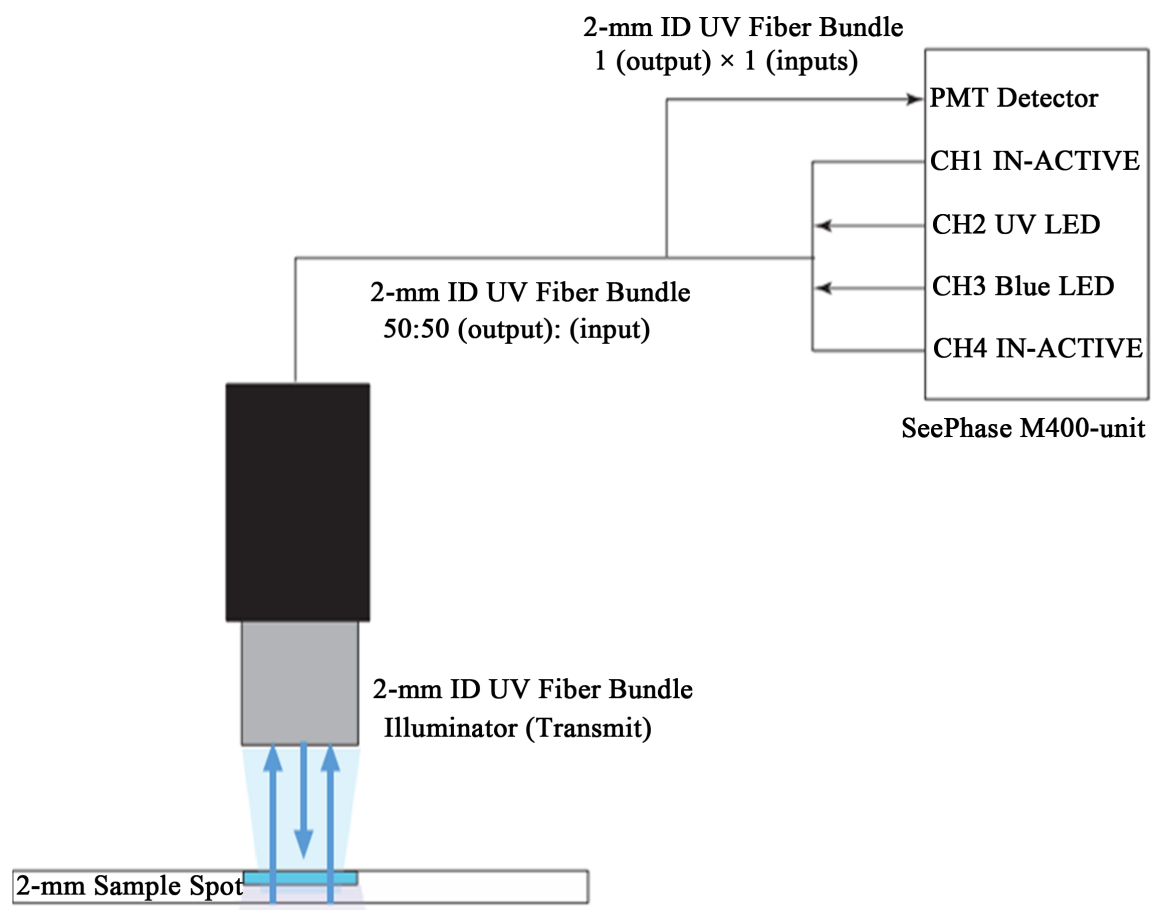

Figure 2. Reflection mode. 


\section{Results}

Results from a number of studies are shown in the following Tables 1-10. The details associated with each study are presented corresponding to each study.

\subsection{Precision}

The intra and inter assay precisions was calculated by measuring UV.D. at 100 points (Replicates) on a slide coated with only C. albicans antigen (Table 11) and 100 points of coated slide plus a low positive serum for C. albicans antibodies using two independent operators (Table 12).

Table 1. The data related to several typical experiments performed to detect IgG antibodies to $H$. pylori antigen in human sera.

\begin{tabular}{cccccc}
\hline Solid phase $\rightarrow$ & CTR & CTTr & DTR & CTTr & NcR \\
\hline Blank & & & & & $0.52^{*}$ \\
Ag & 0.42 & 0.42 & 0.42 & 0.53 & $0.51^{*}$ \\
Ag + Pos1 & 0.39 & 0.31 & 0.39 & 0.35 & $0.47^{*}$ \\
Ag + Neg 2 & & & & & $0.49^{*}$ \\
Ag + Pos + Ab & 0.36 & 0.11 & 0.37 & 0.32 & \\
\hline
\end{tabular}

$\mathrm{C}=$ Clear tap as solid phase $\mathrm{T}=$ Tape, $\mathrm{R}=$ Reflection, $\mathrm{Tr}=$ Transmission, $\mathrm{D}=$ Dark tap as solid phase, $\mathrm{Nc}=$ Nitrocellulose membrane as solid phase, ${ }^{\star}$ Washing step was omitted.

Table 2. The data related to several typical experiments performed to detect IgG antibody to $H$. pylori antigen in human sera. The solid phase used to generate the data presented in this table is a glass slide coated with hydrophilic polymer containing epoxy reactive groups for immobilizing proteins.

\begin{tabular}{ccccc}
\hline Solid phase $\rightarrow$ & Ep Tr & Ep Tr & Ep Tr & Ep Tr \\
& Exp.1 & Exp.2 & Exp.3 & Exp.4 \\
\hline Ag & 0.47 & 0.47 & 0.50 & 0.50 \\
Ag + Pos. & 0.18 & 0.19 & 0.11 & 0.13 \\
Ag + 1/2 pos. & 0.33 & 0.25 & 0.31 & 0.20 \\
Ag + 1/4 Pos. & 0.38 & 0.33 & 0.40 & 0.31 \\
\hline
\end{tabular}

Ep = Epoxy groups, $\mathrm{Tr}=$ Transmission, Exp. $=$ Experiment.

Table 3. The data related to several typical experiments performed to detect IgG antibody to $C$. albicans antigen in a human serum. The solid phase used to generate the data presented in this table is a glass slide coated with hydrophilic polymer containing epoxy reactive groups for immobilizing proteins.

\begin{tabular}{ccccc}
\hline Solid phase $\rightarrow$ & Ep Tr & Ep Tr & Ep Tr & Ep Tr \\
& Exp.1 & Exp.2 & Exp.3 & Exp.4 \\
\hline Ag & 0.49 & 0.49 & 0.44 & 0.44 \\
Ag + Pos. & 0.12 & 0.11 & 0.12 & 0.11 \\
Ag + 1/2 pos. & 0.34 & 0.26 & 0.19 & 0.20 \\
Ag + 1/4 Pos. & 0.43 & 0.37 & 0.26 & 0.33 \\
\hline
\end{tabular}

Ep = Epoxy groups, $\mathrm{Tr}=$ Transmission, Exp. $=$ Experiment 
Table 4. High density amine-binding groups slide, transmission mode for detection of antibodies against Helicobacter pylori antigen.

\begin{tabular}{|c|c|c|c|c|c|c|}
\hline & \multicolumn{2}{|c|}{ UV.D. } & \multicolumn{3}{|c|}{ ELISA (ODs) } & \multirow{2}{*}{ Sera } \\
\hline & Ag alone & Ag plus samples & $\operatorname{Ig} A^{*}$ & $\operatorname{IgG}^{*}$ & $\operatorname{IgM}$ & \\
\hline \multirow{6}{*}{ IgG+ } & 0.49 & 0.39 & 0.560 & 2.211 & 0.447 & 1 \\
\hline & 0.49 & 0.37 & 1.710 & 2.538 & 0.440 & 2 \\
\hline & 0.49 & 0.35 & 3.290 & 3.004 & 0.432 & 3 \\
\hline & 0.45 & 0.32 & 2.773 & 2.177 & 1.097 & 4 \\
\hline & 0.47 & 0.36 & N/D & N/D & $\mathrm{N} / \mathrm{D}$ & 5 \\
\hline & 0.49 & 0.27 & $\mathrm{~N} / \mathrm{D}$ & $\mathrm{N} / \mathrm{D}$ & N/D & 6 \\
\hline \multirow{6}{*}{ IgG- } & 0.49 & 0.47 & $\mathrm{~N} / \mathrm{D}$ & N/D & $\mathrm{N} / \mathrm{D}$ & 7 \\
\hline & 0.49 & 0.46 & $\mathrm{~N} / \mathrm{D}$ & N/D & $\mathrm{N} / \mathrm{D}$ & 8 \\
\hline & 0.49 & 0.43 & $\mathrm{~N} / \mathrm{D}$ & $\mathrm{N} / \mathrm{D}$ & N/D & 9 \\
\hline & 0.49 & 0.46 & $\mathrm{~N} / \mathrm{D}$ & $\mathrm{N} / \mathrm{D}$ & $\mathrm{N} / \mathrm{D}$ & 10 \\
\hline & 0.49 & 0.44 & $\mathrm{~N} / \mathrm{D}$ & N/D & $\mathrm{N} / \mathrm{D}$ & 11 \\
\hline & 0.49 & 0.45 & $\mathrm{~N} / \mathrm{D}$ & $\mathrm{N} / \mathrm{D}$ & $\mathrm{N} / \mathrm{D}$ & 12 \\
\hline
\end{tabular}

*Tested on FDA cleared products. N/D: not done.

Table 5. High density amine-binding groups slide, transmission mode, detecting antibodies to Ds-DNA.

\begin{tabular}{|c|c|c|c|c|}
\hline & \multicolumn{2}{|c|}{ UV.D. } & \multirow{2}{*}{ ELISA $^{\star} \operatorname{IgG}$} & \multirow{2}{*}{ Specimens Sera } \\
\hline & $\mathrm{Ag}^{\star *}$ alone & Ag plus samples & & \\
\hline \multirow{5}{*}{ IgG+ } & 0.50 & 0.33 & + & 1 \\
\hline & 0.48 & 0.30 & + & 2 \\
\hline & 0.50 & 0.34 & + & 3 \\
\hline & 0.48 & 0.26 & + & 4 \\
\hline & 0.50 & 0.43 & + & 5 \\
\hline \multirow{5}{*}{ IgG- } & 0.50 & 0.53 & - & 6 \\
\hline & 0.50 & 0.50 & - & 7 \\
\hline & 0.50 & 0.51 & - & 8 \\
\hline & 0.48 & 0.51 & - & 9 \\
\hline & 0.48 & 0.50 & - & 10 \\
\hline
\end{tabular}

${ }^{\star}$ Tested on a FDA cleared product. ${ }^{*} \mathrm{Ag}$ is not a protein.

Table 6. High density amine-binding groups slide, transmission mode, pregnancy test for detection of hCG hormone.

\begin{tabular}{ccccc}
\hline & UV. D. & & $\begin{array}{c}\text { Lateral flow } \\
\text { Approved device }\end{array}$ & Urine specimens \\
\cline { 1 - 2 } $\mathrm{Ab}^{*}$ alone & Ab Plus samples (Ags) & & + & 1 \\
0.39 & 0.29 & + & $1 / 2$ of 1 \\
0.39 & 0.32 & Weak positive & $1 / 4$ of 1 \\
0.39 & 0.38 & - & $1 / 8$ of 1 \\
0.39 & 0.40 & - & $1 / 16$ of 1 \\
0.39 & 0.40 & + & 1 repeat \\
0.37 & 0.24 & - & $1 / 2$ of 1 \\
0.38 & 0.37 & - & $1 / 4$ of 1 \\
0.38 & 0.36 & - & $1 / 8$ of 1 \\
0.39 & 0.38 & & - & - \\
\hline
\end{tabular}

${ }^{\star}$ Anti-hCG. 
Table 7. High density amine-binding groups slide, transmission mode, detecting antibodies to latex (Allergen).

\begin{tabular}{cccccccc}
\hline \multirow{2}{*}{ Sera } & \multicolumn{3}{c}{ UV.D. } & \multicolumn{2}{c}{ Clinical results } & \multicolumn{3}{c}{ ELISA ODs } \\
\cline { 2 - 8 } & Ag $^{* *}$ alone & Ag plus samples (Abs) & Skin test & Classes & IgE & IgG & IgA \\
\hline 1 & 0.55 & 0.43 & + & IV & 2.341 & 0.473 & 0.367 \\
2 & 0.55 & 0.41 & + & III & 2.002 & 0.511 & 0.305 \\
3 & 0.55 & 0.45 & + & IV & 2.096 & 0.488 & 0.300 \\
4 & 0.55 & 0.37 & + & IV & 2.246 & 0.412 & 0.434 \\
5 & 0.55 & 0.44 & + & IV & 2.213 & 0.554 & 0.385 \\
6 & 0.55 & 0.52 & - & - & 0.029 & 0.475 & 0.396 \\
7 & 0.55 & 0.51 & - & - & 0.024 & 0.313 & 0.363 \\
8 & 0.55 & 0.50 & - & - & 0.054 & 0.404 & 0.492 \\
9 & 0.55 & 0.51 & - & - & 0.037 & 0.418 & 0.555 \\
10 & 0.50 & 0.53 & - & - & 0.025 & 0.564 & 0.419 \\
\hline
\end{tabular}

${ }^{* *} \mathrm{Ag}$ is latex protein.

Table 8. Detection of $H$. pylori antigen in stool test, transmission mode.

\begin{tabular}{|c|c|c|c|c|c|}
\hline \multicolumn{2}{|r|}{ UV.D. } & \multirow{2}{*}{\multicolumn{2}{|c|}{$\begin{array}{c}\text { Lateral flow, stool test } \\
\text { Approved device }\end{array}$}} & \multirow{3}{*}{$\begin{array}{c}\text { Serum } \\
\text { IgG ELISA }\end{array}$} & \multirow{3}{*}{$\begin{array}{c}\begin{array}{c}\text { Stool } \\
\text { Specimens }\end{array} \\
\text { N/A }\end{array}$} \\
\hline $\mathrm{Ab}^{*}$ alone & Ab Plus samples (Ags) & & & & \\
\hline 0.43 & 0.25 & + & $\begin{array}{l}\text { (Positive control) } \\
\text { HpAg in buffer }\end{array}$ & & \\
\hline 0.43 & 0.23 & + & $\begin{array}{c}\text { Negative stool spike } \\
\text { with } \mathrm{HpAg}\end{array}$ & N/A & Spiked negative \\
\hline 0.43 & 0.29 & + & Positive & + & 3 \\
\hline 0.45 & 0.24 & + & Positive & + & 3 repeat \\
\hline 0.43 & 0.28 & + & weak Pos. & $+/-$ & 1 \\
\hline 0.43 & 0.43 & - & Negative & $\mathrm{N} / \mathrm{D}$ & $2^{* *}$ \\
\hline 0.40 & 0.40 & - & Negative & $\mathrm{N} / \mathrm{D}$ & 4 \\
\hline 0.43 & 0.40 & - & Negative & $\mathrm{N} / \mathrm{D}$ & 6 \\
\hline 0.43 & 0.40 & - & Negative & $\mathrm{N} / \mathrm{D}$ & 4 repeat \\
\hline 0.43 & 0.43 & - & Negative & $\mathrm{N} / \mathrm{D}$ & 3 repeat $^{* * *}$ \\
\hline 0.43 & 0.42 & - & Negative & $\mathrm{N} / \mathrm{D}$ & 1 repeat $* * *$ \\
\hline
\end{tabular}

${ }^{*}$ Anti- $H$. pylori. ${ }^{*}$ Treated for $H$. pylori infection 2 months before performing the test. ${ }^{* *}$ Samples were taken immediately after treatment.

Table 9. Strep. A test. Detection of. Strep.A Ag.

\begin{tabular}{|c|c|c|c|c|}
\hline \multicolumn{2}{|c|}{ UV.D. } & \multirow{2}{*}{$\begin{array}{c}\text { Lateral flow } \\
\text { Tested on } \\
\text { proved device }\end{array}$} & & \multirow{2}{*}{$\begin{array}{l}\text { Specimens } \\
\text { Strep. } \\
\text { A. samples }\end{array}$} \\
\hline $\mathrm{Ab}^{*}$ alone & $\begin{array}{c}\text { Ab Plus } \\
\text { samples (Ags) }\end{array}$ & & & \\
\hline 0.46 & 0.29 & + & Positive Control $^{\star *}$ & 1 \\
\hline 0.46 & 0.32 & + & Positive (2) & 2 \\
\hline 0.45 & 0.35 & + & $1 / 22$ & $1 / 22$ \\
\hline 0.45 & 0.37 & + & $1 / 42$ & $1 / 42$ \\
\hline 0.46 & 0.40 & + & $1 / 82$ & $1 / 82$ \\
\hline 0.44 & 0.42 & - & Negative Control ${ }^{\star *}$ & 1 \\
\hline 0.44 & 0.42 & - & Swab taken from a healthy subject & 2 \\
\hline 0.44 & 0.42 & - & Swab taken from a healthy subject & 3 \\
\hline
\end{tabular}

${ }^{\star}$ Anti-Strep. A. ${ }^{*}$ From approved device. 
Table 10. Transmission mode, multiple analytes tests. Detecting antigens and/or antibodies in one run in one spiked specimen.

\begin{tabular}{|c|c|c|c|}
\hline \multirow{2}{*}{ Coated on the slide $\downarrow$} & \multicolumn{2}{|r|}{ UV. D. } & \multirow{2}{*}{$\begin{array}{l}\text { Methods used for } \\
\text { confirmation }\end{array}$} \\
\hline & Base UV.D. & UV.D. after adding the specimen & \\
\hline Anti-H. pylori $\mathrm{Ab}$ & 0.27 & 0.18 & + \\
\hline Anti-Strep. A Ab & 0.25 & 0.13 & + \\
\hline Anti-hCG & 0.27 & 0.11 & + \\
\hline Latex antigen & 0.22 & 0.17 & + \\
\hline
\end{tabular}

Blank $=41$. Specimen $=$ Equal volume of a urine specimen positive for hCG $(50 \%)$ and a serum positive for IgE to latex (allergen) (50\%). Artificial preparation. This mixture was spiked with strep A. antigen and $H$. pylori antigen.

Table 11. Precision of a typical experiment. Slide is coated only with Ag.

\begin{tabular}{cccc}
\hline & \multicolumn{2}{c}{ Intra } & Inter \\
\cline { 2 - 4 } & Operator 1 & Operator 2 & Operators 1 \& 2 \\
\hline Average & 0.514653 & 0.5126 & 0.5112 \\
STDEV & 0.009845 & 0.009494 & 0.009749 \\
$\%$ CV & 1.91299 & 1.852182 & 1.907003 \\
Number & 100 & 100 & 200 \\
\hline
\end{tabular}

Table 12. Precision of a typical experiment. Slide is coated with Ag. plus a weak positive specimens (low $\mathrm{Ab}$ ).

\begin{tabular}{cccc}
\hline & \multicolumn{2}{c}{ Intra } & Inter \\
\cline { 2 - 4 } & Operator 1 & Operator 2 & Operators $1 \& 2$ \\
\hline Average & 0.47396 & 0.4711 & 0.4699 \\
STDEV & 0.01116 & 0.009629 & 0.010466 \\
\%CV & 2.354721 & 2.043935 & 2.227288 \\
Number & 100 & 100 & 200 \\
\hline
\end{tabular}

\subsection{Linearity}

The UV.D. values for two preparations tested independently were obtained using two-fold serial dilutions of each preparation. The protein used for preparations was BSA. The UV.D. values at $280 \mathrm{~nm}$ were compared to $\log 2$ of dilution by standard linear regression. The resulting data are in Figure 3.

\subsection{Performance}

The assay results using 92 confirmed $H$. pylori positive and negative specimens were compared with the results obtained for the same specimens when tested on two FDA cleared predicate kits (IgG and IgA).

Correlation study was conducted on all 92 patients' sera .Of the 92 patients specimens used in this study 80 were negative and 12 were positive for the pre- 


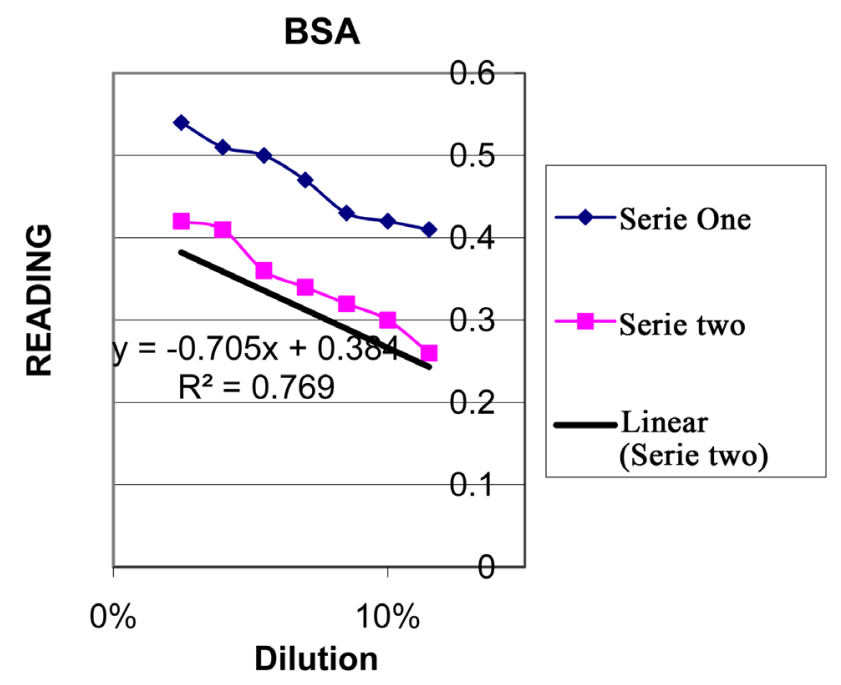

Figure 3. Linearity result.

sence of $H$. pylori antibodies on predicate kits The performance, when using UVLSD device for detection of antibodies to $H$. pylori on tested sera gave the following results:

$$
\begin{aligned}
& \text { Sensitivity }=\mathrm{TP} /(\mathrm{TP}+\mathrm{FN}) \times 100=12 /(12+0) \times 100=100 \% \\
& \text { Specificity }=\mathrm{TN} /(\mathrm{TN}+\mathrm{FP}) \times 100=80 /(80+3) \times 100=96 \% \\
& \text { Efficiency }=(\mathrm{TP}+\mathrm{TN}) /(\mathrm{TP}+\mathrm{TN}+\mathrm{FP}+\mathrm{FN}) \times 100=(12+80) /(12+80+3
\end{aligned}
$$
$+0) \times 100=96.8 \%$

Positive predictive value $=(\mathrm{TP}) /(\mathrm{TP}+\mathrm{FP}) \times 100=(12) /(12+3) \times 100=80 \%$

Negative predictive value $=(\mathrm{TN}) /(\mathrm{TN}+\mathrm{PN}) \times 100=(80) /(80+0) \times 100=$ $100 \%$

\section{Conclusions and Applications}

The UV Laser Spectroscopy Diagnostic method (device) used in this study demonstrated very good performance, as indicated by accepted linearity and low inter and intra $\mathrm{CV}$ values.

Results obtained by testing different type of specimens, (urine, serum, stool or extract of bacteria) show that the device can be used for the detection of antibodies to Helicobacter pylori (Bacteria), Candida albicans (yeast), Ds-DNA (autoimmune marker) and Latex (allergen). Likewise, results show that the device can be used for the detection of antigens of $H$. pylori in stool, Strep. A. in a spiked solution, and hCG (hormone) in urine. Generated results associated with each analyte directly correspond with the results obtained by using predicate devices and methods.

Results demonstrate that in one assay's run, antibodies to a single target antigen (Tables 3-6) or an antigen to a single target antibody can successfully be performed. The device demonstrates accepted data for the detection of IgE antibody to latex allergen and antibody to Ds-DNA.

One important aspect of using the device is its application for detection of multiple antigens, antibodies, or a mixture of antigen/antibody in a single spe- 
cimen to multiple analytes. Table 10 shows that in one assay's run, simultaneous antigens of Sterp. A. and antigen of H.pylori were detected by anti-Strep. A. antibody and anti- $H$. pylori antibody respectively. Table 10 also demonstrates detecting hCG (a hormone) in the same spiked specimen. In the same assay, the latex allergen was used to detect IgE antibody to latex. For evaluation of the device amongst a vast combination of analytes, the specimens used for data generation presented in Table 10 were artificially spiked with the desired analytes.

Our study assessed the clinical utility of the device by using 92 clinically confirmed specimens (Table 13). In this well-controlled study, 12 positive and 80 negative were tested with the predicate FDA cleared kits. The same samples were tested for antibodies to $H$. pylori on the UVLSD device. Data presented in Table 13 manifests the acceptable sensitivity and specificity.

With appropriate modification, the device can be used for the detection of antigens or antibodies in several specimens simultaneously. In this study, we did not use the device for this purpose as for cross-contamination prevention we had to modify the solid phase. This application of the device is particularly useful in the blood bank (for example when detection of antibodies to hepatitis B antigen in many specimens is the aim of running the assay in a short time.) Using the device in this format not only is applicable for screening proposes, but can also be used for detection of specific antibodies e.g. IgG, IgM, IgA or IgE.

The total time for running an assay by the end users is less than 5 minutes. Since a vast combination of assays using desired analytes can be tested on this device and single or multiple results can be obtained in a relatively short time, the device can be considered as an easy to use device for on-site or point of care screening purposes.

The data obtained by testing stools specimens (Table 8) demonstrate that the device can be used for longitudinal follow up of treatment as well. Specimen \# 2 was treated for $H$. pylori infections two months before testing the stool on the device. Also, sample 1 and 3 were tested on the device before and a few days after completion of the treatments.

Another useful opportunity for this device is the discipline of forensic medicine. Since the absorbed antigens or antibodies on the solid phase are proteins, if the device is properly maintained in an appropriate environment, the results of the test can be preserved for several years.

The following are select examples that demonstrate various applications of the device:

Table 13. Assay performance.

\begin{tabular}{ccccc}
\hline Specimens & H. pylori IgG or IgA or IgM or combination of them & UVLSD & Total \\
\hline Positive & 12 & $12(\mathrm{TP})$ & $0(\mathrm{FN})$ & 12 \\
Negative & 80 & $3(\mathrm{FP})$ & $77(\mathrm{TN})$ & 80 \\
Total & 92 & 15 & 77 & 92
\end{tabular}

${ }^{*} H$. pylori ELISA assay results tested on approved predicate. 
1) For major food allergies, a panel of allergens such as peanut, tree nuts, milk, egg, wheat, soy, fish and shellfish can be coated on different spots of the solid phase at the manufacturing facility. On site, the end users may use a single specimen (for example a drop of whole blood obtained from a finger prick) to screen for the presence of IgG (and IgE) antibodies to the above allergens in a rapid manner (food allergies are considered a delayed IgG mediated allergy).

2) Likewise, for other major allergies, a panel of allergens such as dog, penicillin, latex, selected pollens, cat, molds and house dust mite can be coated on different spots of the solid phase at the manufacturing facility. On site, the end users may use a single specimen (for example a drop of whole blood obtained from a finger prick) to screen for the presence of IgE antibodies to the above allergens in a short time. IgE mediated allergies are dangerous and may cause anaphylactic shock and sudden death.

3) One of the main utilities of the device is for emergency purposes. For example, to assess heart failure or a heart attack in rapid manner, a panel consisting of anti-CK, anti-Tn I, anti-Tn T, anti-CRP (not specific), anti-AST, anti-BNP, and anti-GPBB can be coated on different spots of the solid phase at the manufacturing facility. On site, the end users may use a single specimen (for example a drop of whole blood obtained from a finger prick) to determine presence of all or any number of cardiac injury markers which can then be associated with disease severity.

4) In the food industry, for determination of major food borne pathogens in a sample, a panel consisting of anti-Campylobacter jejuni, anti-E.coli O157:H7, anti-Shigella, anti-Salmonella, anti-Listeria, and anti-Noroviruscan be coated on different spots of the solid phase at the manufacturing facility. On site, the end users may use a single sample (for example a drop of meat extract) to determine the presence of all or any one of the contaminants.

5) For determination of autoimmune disorders, a panel (ENA) consisting of SS-A, RNP, SS-B, Jo1, Scl-70 and Sm proteins can be coated on different spots of the solid phase at the manufacturing facility. On site, the end users may use a single specimen (for example a drop of whole blood obtained from a finger prick) and determine the presence of antibodies to all or any one of the coated proteins.

6) For rapid determination of the presence of drugs in urine in criminal cases or for controlled substance prescription and monitoring, a panel of major drugs consisting of antibodies to drugs such as: Marijuana, cocaine, opioid pain relievers, benzodiazepines, heroin, methamphetamine etc. can be coated on different spots of the solid phase at the manufacturing facility. On site, the end users may use a single specimen (mostly urine) and determine the presence of one or more of the coated antibodies.

7) The device can also be used for many other proposes such as testing the HIV P24 protein in blood in emergency room settings or for rapid determination of $\mathrm{D}$-dimer in the operating room. Likewise, the device can be designed for panels utilized in GI pathology, STDs, pulmonology, etc. 
Manufacturing any format of the device should be done following regulations, guidelines and appropriate quality and efficacy measures. The prepared devices should be optimized with the cutoff for each analyte properly established with data related to each analyte stored in the device detector or reader for on-site or point of care evaluation.

\section{References}

[1] Transparency Market Research (2014) Rapid Medical Diagnostic Kits Market (Applications: Clinical Testing, Home-Use, Infectious Disease and Veterinary; Technologies: Lateral Flow Technology, Agglutination Assays, Flow-through and Solid-phase Assays) - Global Industry Analysis, Size, Share, Growth, Trends and Forecast, 2013-2019.

http://www.transparencymarketresearch.com/rapid-medical-diagnostic-kits.html

[2] PRNewswire (2015) Global Rapid Medical Diagnostic Kits Market-2015-2020 Applications and Technologies Analysis of the \$27 Billion Industry.

http://www.prnewswire.com/news-releases/global-rapid-medical-diagnostic-kits-m arket---2015-2020-applications-and-technologies-analysis-of-the-27-billion-industry300089424.html

[3] Markets and Markets (2016) Food Safety Testing Market worth 17.16 Billion USD by 2021 .

http://www.marketsandmarkets.com/PressReleases/food-safety-testing-market.asp 


\section{Abbreviations}

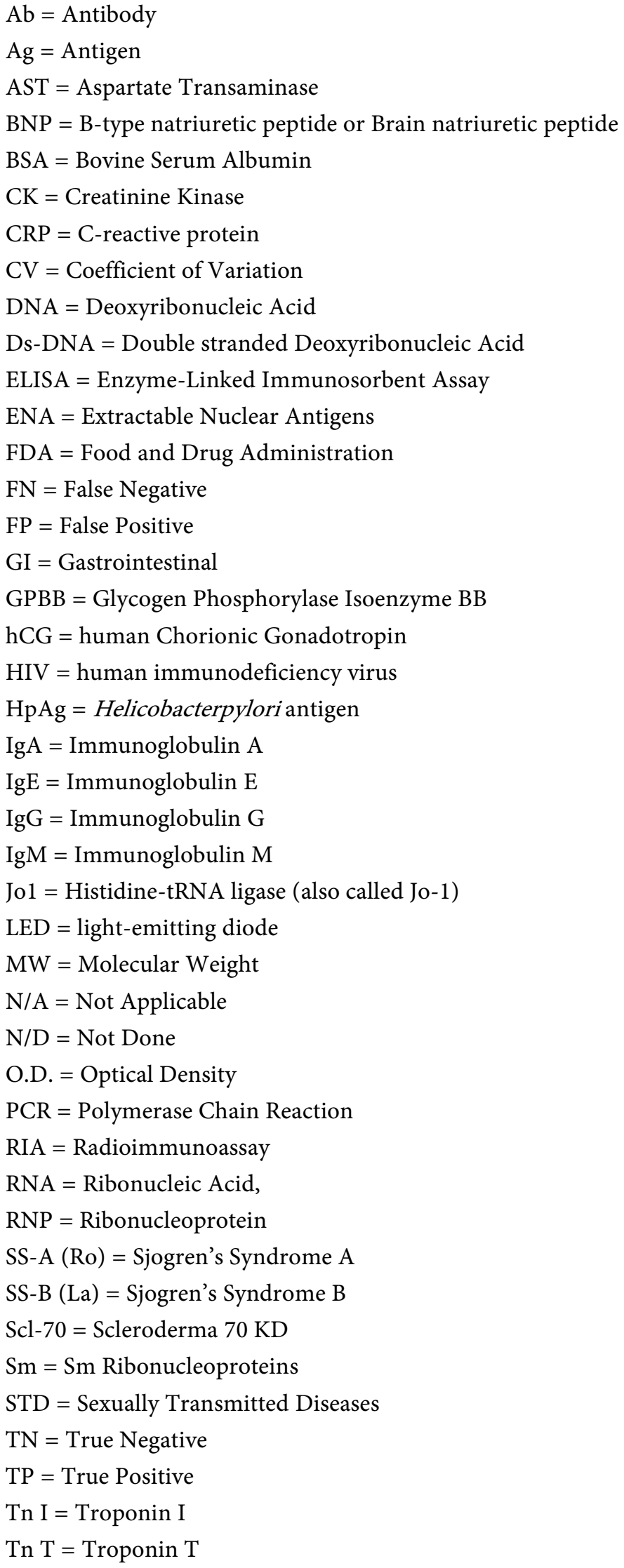


$\mathrm{UV}=$ Ultra Violet

UV. D. = Ultra Violet Density

UVLSD = UV Laser Spectroscopy Diagnostic

Submit or recommend next manuscript to SCIRP and we will provide best service for you:

Accepting pre-submission inquiries through Email, Facebook, LinkedIn, Twitter, etc. A wide selection of journals (inclusive of 9 subjects, more than 200 journals)

Providing 24-hour high-quality service

User-friendly online submission system

Fair and swift peer-review system

Efficient typesetting and proofreading procedure

Display of the result of downloads and visits, as well as the number of cited articles Maximum dissemination of your research work

Submit your manuscript at: http://papersubmission.scirp.org/

Or contact ijcm@scirp.org 